\title{
GROWTH OF THE LUNG IN HEALTHY AND SICK INFANTS
}

\author{
BY \\ STEFAN ENGEL, M.D. \\ (From the Hospital for Sick Children, Great Ormond Street)
}

As correct data on the growth of the lung in infancy are not available, determination of pathological peculiarities of the infant's lung lacks a solid basis. Investigations by Aeby (1880) and a recent publication by Copoletto and Wolbach (1933) do not deal with the live volume of the lung. Aeby determined the volume of the collapsed lung in a few cases. Copoletto and Wolbach gave a statistical survey of the weight of the lungs. The growth of this organ cannot, however, be deduced from the weight; this will become apparent below in the section dealing with the specific weight. In 1935 I published a few observations on lungs which had been fixed by intravenous injection of formalin, the first observations to show the actual volume of the infant's lung. This series of figures indicates roughly the mode of growth (table 1).

TABLE 1

\begin{tabular}{|c|c|c|}
\hline \multirow{2}{*}{$\begin{array}{c}\text { AGE } \\
\text { (MONTHS) }\end{array}$} & \multicolumn{2}{|c|}{ VOLUME (C.C.) } \\
\hline & RIGHT & LEFT \\
\hline $\begin{array}{r}1 \\
2 \\
4 \\
8 \\
18\end{array}$ & $\begin{array}{r}62 \\
53 \\
60 \\
112 \\
250\end{array}$ & $\begin{array}{r}48 \\
45 \\
45 \\
79 \\
210\end{array}$ \\
\hline
\end{tabular}

\section{Anatomical investigations}

The present investigations have been carried out in order to determine the actual volume of the expanded lung. This was intended to form the basis for investigations on the structure of the growing lung.

Method. The lungs were inflated under constant and controlled pressure. Compressed air (with the help of a water jet pump) was introduced into a flask closed by a thrice perforated rubber stopper: two of the perforations were for the entry and exit of the air, and the third was connected to a U-shaped 
water manometer. Increased pressure had to be applied during the first inflation owing to the internal cohesion of the collapsed bronchioli and airspaces. In subsequent inflations a much lower pressure proved effective. Pressure of 12-15 c.c. water, corresponding to the intrapleural (negative) pressure, restored the size and shape of the lung satisfactorily. Farber and Wilson (1933) obtained analogous results when determining the negative pressure necessary to expand the atelectatic lungs of newborn infants, using a Drinker respirator.

The lungs were allowed to remain under pressure until they were dry, and then placed in a $37^{\circ} \mathrm{C}$. incubator where their weight became constant within a couple of days. The volume of the dried lung was determined by displacement.

TABLE 2

ACTUAL VOLUME OF THE RIGHT LUNG

\begin{tabular}{|c|c|c|c|c|c|c|c|c|c|}
\hline \multirow{3}{*}{ No. } & \multicolumn{3}{|c|}{ INFANT } & \multicolumn{6}{|c|}{ LUNG } \\
\hline & \multirow{2}{*}{$\begin{array}{c}\text { AGE } \\
\text { (MONTHS) }\end{array}$} & \multirow{2}{*}{$\begin{array}{c}\text { WEIGHT } \\
\text { (GRAMMES) }\end{array}$} & \multirow{2}{*}{$\begin{array}{l}\text { HEIGHT } \\
\text { (CM.) }\end{array}$} & \multirow{2}{*}{$\begin{array}{l}\text { VOLLME } \\
\text { (c.C.) }\end{array}$} & \multicolumn{2}{|c|}{ WEIGHT (GM.) } & \multirow{2}{*}{\begin{tabular}{|c} 
DRIED \\
SL'BSTANCE \\
(PER \\
CENT.)
\end{tabular}} & \multicolumn{2}{|c|}{ VOLUME PER GM. } \\
\hline & & & & & FRESH & DRIED & & $\begin{array}{l}\text { FRESH } \\
\text { (C.C.) }\end{array}$ & $\begin{array}{l}\text { DRIED } \\
\text { (C.C.) }\end{array}$ \\
\hline $\begin{array}{l}1 \\
2 \\
3 \\
4 \\
5 \\
6 \\
7 \\
0\end{array}$ & $\begin{array}{l}2 \\
0 \\
2 \\
1 \\
3 \\
4 \\
4 \\
5\end{array}$ & $\begin{array}{l}2000 \\
2300 \\
3100 \\
2350 \\
3300 \\
36500 \\
3700 \\
3700\end{array}$ & $\begin{array}{l}48 \\
48 \\
53 \\
50 \\
54 \\
58 \\
58 \\
58\end{array}$ & $\begin{array}{r}57 \\
75 \\
77 \\
88 \\
97 \\
100 \\
110 \\
120\end{array}$ & $\begin{array}{l}33 \\
32 \\
40 \\
30 \\
31 \\
33 \\
45 \\
49\end{array}$ & $\begin{array}{l}6.7 \\
6.0 \\
8 \cdot 3 \\
5 \cdot 8 \\
6.5 \\
7 \cdot 2 \\
9.0 \\
9.3\end{array}$ & $\begin{array}{l}20 \cdot 3 \\
19 \cdot 0 \\
20 \cdot 7 \\
19 \cdot 7 \\
20 \cdot 8 \\
22 \cdot 1 \\
20 \cdot 0 \\
19 \cdot 0\end{array}$ & $\begin{array}{l}1 \cdot 8 \\
2 \cdot 4 \\
1 \cdot 9 \\
2 \cdot 9 \\
3 \cdot 0 \\
3 \cdot 1 \\
2 \cdot 4 \\
2 \cdot 4\end{array}$ & $\begin{array}{r}8 \cdot 5 \\
12 \cdot 5 \\
9 \cdot 0 \\
15 \cdot 2 \\
15 \cdot 0 \\
14 \cdot 0 \\
12 \cdot 0 \\
13 \cdot 0\end{array}$ \\
\hline $\begin{array}{r}9 \\
10 \\
11 \\
12 \\
13\end{array}$ & $\begin{array}{r}11 \\
7 \\
12 \\
7 \\
11\end{array}$ & $\begin{array}{l}4200 \\
7100 \\
9300 \\
6000 \\
9200\end{array}$ & $\begin{array}{l}61 \\
68 \\
73 \\
73 \\
73\end{array}$ & $\begin{array}{l}145 \\
185 \\
200 \\
230 \\
310\end{array}$ & $\begin{array}{l}86 \\
56 \\
74 \\
62 \\
92\end{array}$ & $\begin{array}{l}14.7 \\
11.9 \\
15.2 \\
15.8 \\
18.6\end{array}$ & $\begin{array}{l}17.0 \\
21.0 \\
20.5 \\
25.5 \\
20.2\end{array}$ & $\begin{array}{l}1 \cdot 7 \\
3 \cdot 3 \\
2 \cdot 7 \\
3 \cdot 9 \\
3 \cdot 4\end{array}$ & $\begin{array}{l}10 \cdot 0 \\
15 \cdot 0 \\
13 \cdot 0 \\
14 \cdot 5 \\
17 \cdot 0\end{array}$ \\
\hline
\end{tabular}

Discussion. The lung inflated by pressure equivalent to the intrapleural pressure corresponds satisfactorily to the actual size of the breathing lung and thus affords the nearest estimate to the amount of functional lung tissue. The results are collected in table 2 and in the curve II of fig. 1. The diagram shows the volume almost continuously increasing. There is, however, something unusual in the shape of the curve. It rises slowly during the first few months and then ascends steeply; in other words, the growth of the lung, in my cases is very slow in the first few months and proceeds rapidly in the second half of the first year.

This result contrasts with the general rule of growth in infancy, i.e. the growth of the body proceeds rapidly in the first few months, far more rapidly than at any other age. Slow growth of so vital an organ as the lung and a rapidly developing body with its increased need of oxygen appear to be incompatible from a morphological as well as from a functional point of view. Further investigations appeared necessary. 


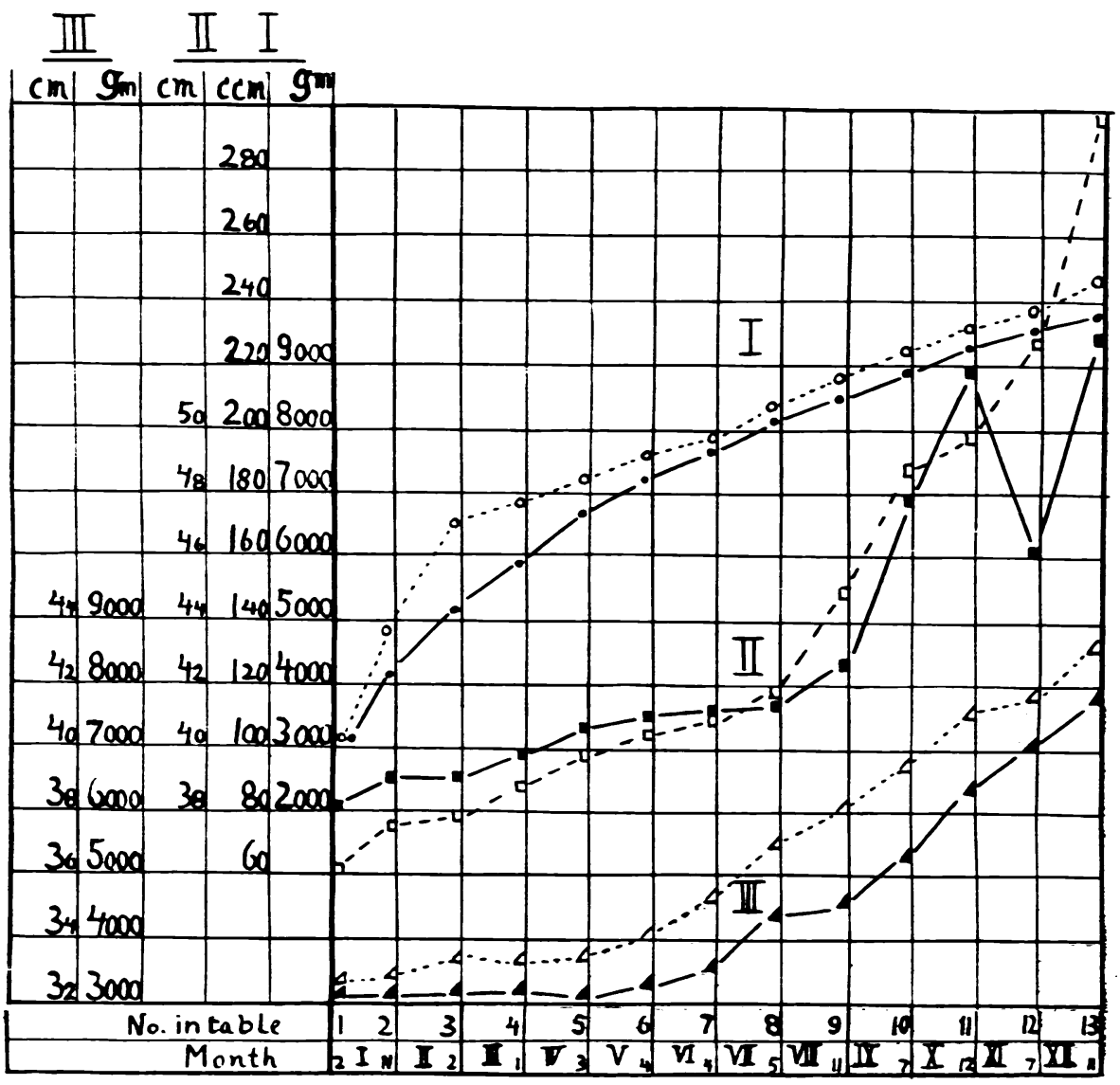

FIG. 1.-To show in I and III body-weight and circumference of the chest (after Zeltner). Curve I is that of a normal infant, curve III that of an infant which suffered from pyloric stenosis and recovered. Curve II shows the body-weight and the actual volume of the lung of anatomical cases.

The figures at the bottom of the diagram correspond in the first row to the cases in table 2. In the second row are the months, in their natural order, indicated by Latin numerals and the actual age of the cases of table 2 by small Arabic numerals.

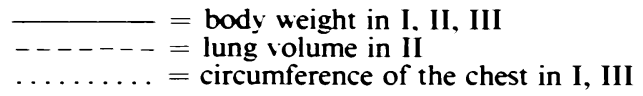

\section{Thorax and lung}

Thorax and lung are reciprocally dependent on each other. In the growing lung, development is only possible if thoracic space is available; otherwise the lung remains under-developed. I was able to prove this directly (Engel and Grueneberg, 1940). The material was furnished by the lungs of a lethal mutation in the rat. The anomaly in question was a hereditary (recessive) hypertrophy of the thoracic cartilage. The growth of the ribs was definitely arrested by the hypertrophy of the cartilage, and the chest remained small and deformed. The lungs were small (as compared with the lungs of rats of the same litter and the same age), and their structure was as foetal as it is normally 
in the lung of the newborn rat; according to the age, the lungs should have been fully developed and differentiated. Arrest of the growth and development of the lungs in rats with a narrow and fixed thorax admits of only one interpretation: the small space available in the deformed chest kept the lung in the undeveloped state characteristic of the lung of the newborn rat.

Clinical investigations. The intimate relationship between thorax and lung gives the opportunity of following clinically the development of the chest and lung in healthy as well as in sick infants. For this purpose the external measurements of the chest, particularly the circumference, are used; internal measurements, taken from skiagrams, serve the purpose still better.

Zeltner (1911), using the former method, made many observations on the circumference of the chest, and came to the following conclusion: the circumference increases normally from 38 to $46 \mathrm{~cm}$. in the first three months, and from 46 to $51 \mathrm{~cm}$. in the subsequent nine months. This means that more than 60 per cent. of the total growth in the first twelve months is completed within the first three months, a rate of progress which exceeds even that of bodygrowth (fig. 1). The growth of the chest (circumference) slows down or even comes to a standstill when the infant ceases to gain weight. Figures of the body-weight and of the circumference of the chest are almost parallel both in normal and pathological cases.

I can support and amplify these rough observations by radiological investigations. The skiagram shows not only the internal width, but also the height of the thoracic cavity. The method is superior to that already mentioned in that it gives two measurements instead of one and, moreover, is not rendered inaccurate by the soft parts covering the thorax which vary individually and cannot be calculated.

TABLE 3

AVERAGE FIGURES OF THE INTERNAL MEASUREMENTS

\begin{tabular}{|c|c|c|c|c|c|}
\hline Months & . & 0 & 3 & 6 & 12 \\
\hline \multicolumn{2}{|c|}{ Transverse diameter $(\mathrm{cm})}$. & $8 \cdot 5$ & 11.0 & 12.0 & $14-0$ \\
\hline Height (cm.) & . & $4 \cdot 5$ & $6 \cdot 5$ & 7.0 & $8 \cdot 5$ \\
\hline
\end{tabular}

The increase in the transverse diameter amounts to 46 per cent. in the first three months, and to 64 per cent. in the first six months (the percentage relating to the total increase within the first twelve months). Similar conditions are seen in the increase in height (diaphragm to apex on the right side). The figures are 50 per cent. and 62 per cent. respectively.

My observations are corroborated by the figures published in two American papers, the first (Maresh and Washburn, 1938) dealing primarily with measurements of the heart in skiagrams, the second (Farell, 1930) with measurements of the chest of newborn infants.

The clinical investigations lead to the unequivocal conclusion that the chest (lung) of the normal infant grows fastest in the first three months. This is in 
accordance with the general growth of the body. Impairment of the general condition as indicated by the loss of or stationary weight is intimately reflected in the growth of the chest. This follows from the clinical investigations of healthy and sick infants.

\section{Specific weight of the lung}

Specific weight is found to be an important feature of the growth of the lung which cannot be disregarded in the present considerations. Simultaneous determinations of volume, fresh and dry weight of the lung (table 2) show a definite relationship between size of the lung and specific weight. The lung tissue becomes lighter as age and size increase; in other words, small lungs are relatively heavier than larger lungs. The approximate figures in my series are 2.0 to 2.5 c.c. lung tissue per gramme fresh weight in younger, and 3.0 to 3.5 c.c. in older infants. Analogous figures are obtained in relation to dry weight. The decrease in specific weight is still more impressive in older children; I found 5.5 c.c. lung tissue (volume of right lung 453 c.c.) per gramme fresh weight in a child aged four years.

It may be emphasized that the specific weight is not primarily dependent on the age but on the size of the lungs, however parallel the increase may appear. Comparison of cases 11 and 13 is significant in this connexion. The two infants were almost identical as regards age, weight and height; the volume of the lungs, however, was different, viz. 200 and 310 c.c. respectively. The result of estimation of the specific weight is conclusive: the larger lung of case 13 was considerably lighter than the smaller of case 11. This individual example also illuminates the interrelationship between specific weight and volume more strikingly than the series of cases with all the changes due to chance (such as blood content) and technique.

Taking into account the decrease of specific weight as the volume of the lung increases, the weight must be rejected as a test for size and growth of the lung. The excellent paper of Copoletto and Wolbach with its many figures cannot, therefore, be used for the solution of the present problem.

\section{Growth of the lung and general condition}

The contrast between the anatomical and clinical findings appears inexplicable at first sight. However, the measurements of the chest in less thriving or wasting infants provide the clue to the problem. The growth of the chest and the lung depends simply on the general condition of the infant. Fig. 1 makes this plausible enough. All the specimens of my anatomical series came from infants far below standard weight, whereas the weight of the older infants approximates to the average with the sole exception of case 9. This case will be considered separately. On the other hand, the curve of my cases (II) differs entirely from that of a normal clinical case (I), but resembles closely the curve of an infant (III) which, whilst wasting during the first few months, gained weight in the subsequent period. The curves II and III have the following 
points in common: poor general condition in the first few months and good progress in subsequent months; slow growth of the chest or lung at first, and good or even rapid advance later. The interrelationship of the weight on the one hand, and the lung volume or chest dimensions on the other can hardly be disputed. The conclusion is supported by the constancy of the relationship, indicated above in one striking example, in many cases.

The anatomical material of hospitals obviously affords little opportunity of corroborating directly the different mode of growth of the lung in normal and in pathological cases. Two of my anatomical cases, however, illustrate well the preponderating influence of the general condition (table 4).

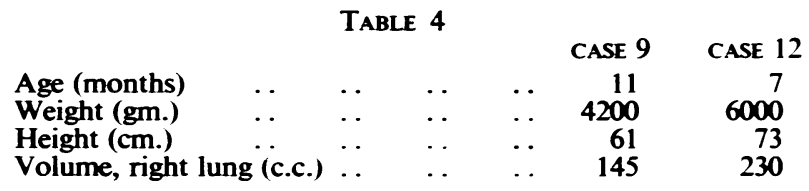

Case 9 was a much under-developed infant suffering from spastic diplegia, whereas the seven-months-old infant, No. 12, was taller than normal, the weight having been reduced rapidly. The relative size of the two lungs is significant: the older but undersized and emaciated infant had a small and the younger rather over-developed infant a large lung.

Further substantial support for the assumption that growth of the lung is arrested in wasting infants is provided histologically. The pulmonary structure of the newborn infant is so peculiar (observations to be published in detail later) that it can be recognized in any histological section. The acini are so small, to mention only one of the essential features, that full-length ductuli are met in any section. This characteristic picture persists for months in the lung of the wasting infant, a documentary proof of the developmental arrest.

Clinical and anatomical results point likewise to the connexion between growth of the lung and the infant's general condition.

\section{General growth and growth of the lung}

The arrest of the pulmonary growth in less thriving and in wasting infants presents a unique problem. The general body-growth is impaired in wasting infants only slightly or not at all; the lung, on the other hand is not only involved in severe cases, but impairment in its growth follows even any slight change in the general condition. I suggest the following explanation: The metabolism of the infant slows down whenever its general condition is impaired, less oxygen is required and superficial respiration results. The expansion of the chest, the stimulus to the growth of the thorax, is thus diminished and the chest ceases to grow. This again reacts upon the development of the lung because its growth depends on the space available. On the other hand, the reduced respiration may be a handicap to the restoration of normal metabolism. It is a vicious circle beginning with the metabolic disturbance which initiates or accompanies the loss of, or standstill in, weight. 
The normal growth of the lung

Combined evaluation of the anatomical and clinical investigations leads to the following data on the growth of the lung in infancy. The right lung of the newborn infant has a volume of 60 to 70 c.c.; this volume is doubled in the first three to four months and quadrupled towards the end of the first twelve months. The left lung is smaller than the right lung (table 1); its volume amounts to 75 to 80 per cent. of that of the right lung. The decrease in the specific weight indicates that, apart from the growing volume, the relative amount of functional tissue increases as the age and volume increase.

\section{Clinical importance}

The relationship between wasting of the infant and its respiration has never been considered. The interest of paediatricians has been focussed on the intestinal and metabolic disturbances which are responsible for the deterioration of the general condition.

The impaired growth of the lung explains first the high incidence of collapse and pneumonia in wasting infants; and also suggests a new form of treatment. It might be possible to improve the general condition by influencing the respiration and thus breaking the vicious circle. This might be a considerable help in difficult dietary treatment. This question can, however, be settled only in the wards.

\section{Summary}

The lung of the normal infant grows fastest in the first few months. It doubles its volume in the first three to four months and quadruples it by the end of the first year.

The growth of the lung reacts in infancy to the slightest change, positive as well as negative, of the general condition, and comes to an almost complete standstill in wasting infants. This implies not only that the lung remains small, but also that the structural differentiation of the tissue is arrested at an early stage.

The arrest of growth and differentiation of the lung explains the high rate of collapse and pneumonia in wasting infants. On the other hand, recognition of the pulmonary impairment suggests that respiratory therapeutics may be an additional aid in the treatment of wasting infants.

Thanks are due to the medical committee of the Hospital for Sick Children, Great Ormond Street, who afforded the opportunity of carrying out the anatomical investigations and particularly to Dr. D. Nabarro, late Director of the Pathological Department. Thanks are also due to Dr. G. H. Newns and Dr. Ruby O. Stern for kind assistance. 


\section{REFERENCES}

Aeby, C. (1880). Der Bronchialbaum der Säugethiere und des Menschen, Leipzig.

Copoletto, J. M., and Wolbach, S. B. (1933). Amer. J. Path., 9, 55.

Engel, S. (1935). In Pfaundler, M., and Schlossmann, A., The diseases of children, edited by Peterman, M. G., Phila., 4, 440.

Engel, S., and Grueneberg, H. (1940). J. Genet., 39, 343.

Farber, S., and Wilson, J. L. (1933). Amer. J. Dis. Child., 46, 572.

Farell, J. T. (1930). Amer. J. Roentgen., 24, 140.

Maitland-Jones, A. (1933). In Parsons, L. G., and Barling, S., Diseases of infancy and childhood, London, 1, 16.

Maresh, M. M., and Washburn, A. H. (1938). Amer. J. Dis. Child., 56, 37.

Zeltner, A. (1911). Jhrb. Kinderheilk., 74, 153. 